\title{
Resin Bonding of Self-Etch Adhesives to Bovine Dentin Bleached from Pulp Chamber
}

\author{
Akiko Haruyama, ${ }^{1}$ Atsushi Kameyama, ${ }^{1}$ Junji Kato, ${ }^{1,2}$ Shinji Takemoto, ${ }^{3}$ Yutaka Oda, \\ Eiji Kawada, ${ }^{2}$ Toshiyuki Takahashi, ${ }^{4}$ and Masahiro Furusawa ${ }^{1}$ \\ ${ }^{1}$ Department of Endodontics and Clinical Cariology, Tokyo Dental College, 2-9-18 Misaki-cho, Chiyoda-ku, Tokyo 101-0061, Japan \\ ${ }^{2}$ Department of Cariology and Operative Dentistry, Division of Oral Health Sciences, Graduate School of Medical and Dental Sciences, \\ Tokyo Medical and Dental University (TMDU), 1-5-45 Yushima, Bunkyo-ku, Tokyo 113-8549, Japan \\ ${ }^{3}$ Department of Dental Materials Science, Tokyo Dental College, 2-9-18 Misaki-cho, Chiyoda-ku, Tokyo 101-0061, Japan \\ ${ }^{4}$ Division of General Dentistry, Tokyo Dental College Chiba Hospital, 1-2-2 Masago, Mihama-ku, Chiba 261-8502, Japan
}

Correspondence should be addressed to Atsushi Kameyama; kameyama@tdc.ac.jp

Received 16 June 2016; Accepted 30 August 2016

Academic Editor: Ali I. Abdalla

Copyright (C) 2016 Akiko Haruyama et al. This is an open access article distributed under the Creative Commons Attribution License, which permits unrestricted use, distribution, and reproduction in any medium, provided the original work is properly cited.

\begin{abstract}
This study evaluated the microtensile bond strength ( $\mu$ TBS) of 1-step self-etch adhesives (1-SEAs) and 2-step self-etch adhesives (2SEAs) to pulp chamber dentin immediately after bleaching with 2 types of common bleaching techniques. Pulp chamber dentin of bovine teeth was bleached using $30 \%$ hydrogen peroxide $\left(\mathrm{H}_{2} \mathrm{O}_{2}\right)$ solution with quartz-tungsten-halogen light-curing unit (Group 1) and 3.5\% $\mathrm{H}_{2} \mathrm{O}_{2}$-containing titanium dioxide $\left(\mathrm{TiO}_{2}\right)$ (Pyrenees $\left.{ }^{\circledR}\right)$ activated with 405-nm violet diode laser for $15 \mathrm{~min}(\mathrm{Group} 2)$. Unbleached specimens were placed in distilled water for $15 \mathrm{~min}$ and used as controls. After treatment, dentin was bonded with resin composite using 1-SEA or 2-SEA and stored in water at $37^{\circ} \mathrm{C}$ for $24 \mathrm{~h}$. Each specimen was sectioned and trimmed to an hourglassshape and $\mu$ TBS was measured. Fractured specimens were examined under a scanning electron microscope to determine fracture modes. All specimens in Group 1 failed before proper bonding tests. In Group 2, the $\mu$ TBS of 2-SEA was significantly greater (with no failed specimens) than 1-SEA (where 21 out of 36 failed). These results indicate that 2-SEA is a better adhesive system than 1-SEA on bleached dentin. Our results also demonstrated that application of $\mathrm{H}_{2} \mathrm{O}_{2}$ significantly decreases bond strength of resin to dentin; however, in the case of nonvital tooth bleaching, Pyrenees ${ }^{\circledR}$ is a better alternative to the conventional $30 \% \mathrm{H}_{2} \mathrm{O}_{2}$ bleaching.
\end{abstract}

\section{Introduction}

Tooth bleaching techniques such as the walking bleach technique, also known as internal bleaching technique, are common treatment methods to manage esthetic concerns regarding discolored nonvital teeth caused by pulpal necrosis or by past history of root canal treatment $[1,2]$. A common component of tooth bleaching agents is hydrogen peroxide $\left(\mathrm{H}_{2} \mathrm{O}_{2}\right)$ which when catalyzed by $405-\mathrm{nm}$ violet laser irradiation generates oxygen hydroxyl radicals and other species that decompose organic pigments on the teeth thereby removing dental colorants [3-6]. After bleaching nonvital teeth, endodontic access cavities are usually filled with resin composite.

The 2-step self-etch adhesive (2-SEA) system has been recognized as the "gold standard" and this system has been widely used for bonding during direct composite restoration [7]. Since the bonding agent contains acidic monomers, both the enamel and dentin can be simultaneously conditioned and primed and the etch-and-rinse phase is no longer necessary. In particular, the "mild" self-etch adhesives demineralize only the dentin to a shallow degree while leaving hydroxyapatite crystals around the collagen fibrils. This type of adhesion prevents the degradation of resin-dentin interface caused by excessive demineralization [8]. In recent years, the 1-step self-etch adhesives (1-SEAs), also known as the "all-in-one" adhesives, have become commercially available [9]. The 1-SEAs are complex mixtures with both hydrophilic and hydrophobic components containing large amounts of solvents, such as acetone, ethanol, and water. This system enables the combining of etching, priming, and bonding 
TABLE 1: Test groups.

\begin{tabular}{lcc}
\hline & Agent & Light activation \\
\hline Control & Water & - \\
Group 1 & $30 \% \mathrm{H}_{2} \mathrm{O}_{2}$ & Optilux 501 \\
Group 2 & $3.5 \% \mathrm{H}_{2} \mathrm{O}_{2}+\mathrm{TiO}_{2}$ & 405-nm diode laser \\
\hline
\end{tabular}

phase into 1 step, consequently simplifying the restoration process and reducing chair time [10].

The bonding behavior of 1-SEAs is different than that of 2-SEAs because, even after high-pressure air blow, polymerization rate and adhesive strength decrease due to their high hydrophilicity when solvent removal before light curing is not complete. As a result, the bonding behavior of 1SEA on bleaching agent-applied dentin may also differ from that of 2-SEA. The purpose of this study was to evaluate the microtensile bond strength $(\mu \mathrm{TBS})$ of 1-SEA and 2-SEA to pulp chamber dentin immediately after bleaching with 2 types of common bleaching techniques. The null hypothesis is that there is no difference between the bonding behaviors of 1-SEA and 2-SEA on bleached dentin.

\section{Materials and Methods}

2.1. Tooth Preparation. Thirty bovine teeth, which were frozen after extraction to maintain freshness, were defrosted and the tooth crown was cut $3 \mathrm{~mm}$ below the cement-enamel junction. Each crown was sectioned mesiodistally along the long axis and the surface was ground using \#400 SiC paper exposing the enamel and labial pulpal chamber dentin. The specimens were randomly divided into 3 groups of 10 teeth (Table 1).

2.2. Test Groups. For Group 1, pulp chamber dentin was treated with $30 \% \mathrm{H}_{2} \mathrm{O}_{2}$ solution (Wako Pure Chemical Industries, Osaka, Japan, $\mathrm{pH}$ 3.35). The bleached surface was irradiated with a quartz-halogen-tungsten light-curing unit (Optilux 501, Kerr Hawe, Bioggio, Switzerland) for $15 \mathrm{~min}$ at a distance of $1 \mathrm{~mm}$ from the tip of the light source. The diameter of the irradiated area was about $8 \mathrm{~mm}$ and the power density was $720 \mathrm{~mW} / \mathrm{cm}^{2}$.

For Group 2, pulp chamber dentin was treated with 3.5\% $\mathrm{H}_{2} \mathrm{O}_{2}$-based bleaching agent containing $\mathrm{TiO}_{2}$ (Pyrenees, Mitsubishi Gas Chemical Co., Tokyo, Japan, lot number 07P0601). In order to activate the photocatalytic effect of $\mathrm{TiO}_{2}$, the bleached surface was irradiated with 405-nm violet diode laser (VLM 500, Sumitomo Electric Industries, Yokohama, Japan) for $15 \mathrm{~min}$. The laser was delivered through an optical fiber with a core diameter of $800 \mu \mathrm{m}$. The specimen was placed at a distance of $15 \mathrm{~mm}$ from the fiber tip to obtain an irradiated area of $8 \mathrm{~mm}$ in diameter $[11,12]$. Energy levels were measured periodically with a power meter (LaserMate$\mathrm{P}$, Coherent, CA) in order to maintain irradiation at a power density of $800 \mathrm{~mW} / \mathrm{cm}^{2}$.

The last group served as the control where pulp chamber dentin was placed in distilled water for $15 \mathrm{~min}$.
After treatment, one specimen from each group was dehydrated and dried, placed on aluminum stab, coated with Au-Pd using an automatic sputter coater (SC500A, VG Microtech, East Sussex, UK), and surface-observed using scanning electron microscope (SEM, JSM-6340F, JEOL, Tokyo, Japan) at $15 \mathrm{kV}$.

2.3. Specimen Preparation for $\mu$ TBS. After treatment, specimens were rinsed with running tap water for 1 min and airdried using a triple syringe. Clearfil $S^{3}$ Bond and Clearfil SE Bond were used as 1-SEA and 2-SEA, respectively (Table 2). 1-SEA was applied on the treated dentin surface using a disposable brush for $20 \mathrm{~s}$, followed by strong air-drying using a three-way syringe, and then light-cured for $10 \mathrm{~s}$ using quartztungsten-halogen light-curing unit (Optilux 501). Thereafter, resin composite (Clearfil AP-X, Kuraray Noritake Dental, shade A2) was built up incrementally in 5 steps and lightcured for $40 \mathrm{~s}$ each using Optilux 501 to a height of $5 \mathrm{~mm}$.

2-SEA was applied under the manufacturer's instructions as in 1-SEA (cited from our previous study) [13].

The bonded specimens were stored in water at $37^{\circ} \mathrm{C}$ for $24 \mathrm{~h}$ and then sectioned $(0.7 \mathrm{~mm})$ in a mesial-distal direction using a low-speed diamond saw (Isomet, Buehler, Lake Bluff, IL, USA). Four slabs were obtained from each tooth. The slabs were modified to an hourglass-shape at the bonded interface and standardized to produce a bonded area of $1.0 \pm 0.2 \mathrm{~mm}^{2}$ using a superfine diamond bur (SF-114, Shofu, Kyoto, Japan) and high-speed handpiece under copious airwater spraying. Specimens were attached to Bencor Multi-T device (Danville Engineering, San Ramon, CA, USA) using cyanoacrylate glue (Model Repair II Blue, Dentsply-Sankin, Otawara, Japan) and the $\mu$ TBS was measured on a universal testing machine (Tensilon RTC-1150-TSD, Orientec, Tokyo, Japan) at a crosshead speed of $1.0 \mathrm{~mm} / \mathrm{min}$. After calculating the exact area of each fractured surface after measuring the dimensions with a digital caliper (CD-15 CPX, Mitutoyo, Tokyo, Japan), $\mu$ TBS ( $\mathrm{MPa}$ ) was measured by dividing the recorded force $(\mathrm{N})$ at the time of fracture by the bond area $\left(\mathrm{mm}^{2}\right)$ (Figure 1). If a specimen failed before proper testing, a bond strength of $0 \mathrm{MPa}$ was used for statistical analyses. The number of pretesting failures was also noted.

After $\mu$ TBS testing, the fractured dentin-side of each specimen was placed on an aluminum stub, Au-Pd-coated, and examined under SEM (SEM: JSM-6340F, JEOL, Tokyo, Japan) to determine the mode of failure.

2.4. Statistical Analysis. Bonding behavior of 1-SEA and 2SEA and bleaching techniques was compared using two-way analysis of variance (2-way ANOVA) and post hoc TukeyKramer multiple comparison test at a significance level of 5\% using the IBM SPSS 18 statistical software (SPSS Inc., Chicago, IL, USA).

\section{Results}

3.1. SEM Observation of Treated Dentin Surface. Dentinal tubules of pulpal chamber were exposed in the bleach treated groups (Figures 2(b) and 2(c)) compared to control with 
TABLE 2: Dental adhesives used in this study.

\begin{tabular}{lllll}
\hline Code & Product & Components & pH & Application protocol \\
\hline 1-SEA & $\begin{array}{l}\text { Clearfil S }{ }^{3} \text { Bond } \\
\text { Kuraray Noritake Dental, } \\
\text { Kurashiki, Japan }\end{array}$ & $\begin{array}{l}\text { 10-MDP, Bis-GMA, HEMA, initiator ethanol, } \\
\text { water, stabilizer, filler, hydrophobic } \\
\text { dimethacrylate }\end{array}$ & $\begin{array}{l}\text { (1) Apply adhesive for 20 s } \\
\text { (2) Relatively strong stream of air } \\
\text { for drying } \\
\text { (3) Light cure for 10 s }\end{array}$ \\
\hline \multirow{2}{*}{ 2-SEA } & $\begin{array}{l}\text { Clearfil SE Bond } \\
\text { Kuraray Noritake Dental, } \\
\text { Kurashiki, Japan }\end{array}$ & $\begin{array}{l}\text { Primer: 10-MDP, HEMA, hydrophilic DMA, } \\
\text { photoinitiator, aromatic tertiary amine, water } \\
\text { Bonding: 10-MDP, Bis-GMA, HEMA, } \\
\text { hydrophobic DMA, photoinitiator, aromatic } \\
\text { tertiary amine, silanized colloidal silica }\end{array}$ & $\begin{array}{l}\text { (1) Apply primer for 20 s } \\
\text { (2) Gently air-drying }\end{array}$ \\
& & & $\begin{array}{l}\text { (3) Apply bonding agent } \\
\text { (4) Light cure for 20 s }\end{array}$ \\
\hline
\end{tabular}
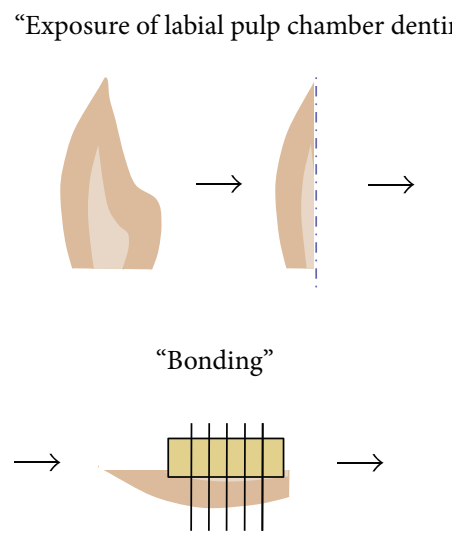

Built up composite on treated surface and then sectioned the bonded specimens perpendicularly to tooth axis
"Bleaching"

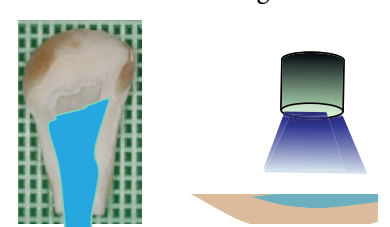

Applied bleaching agent to pulp chamber dentin surface and activate it using laser or light-curing unit

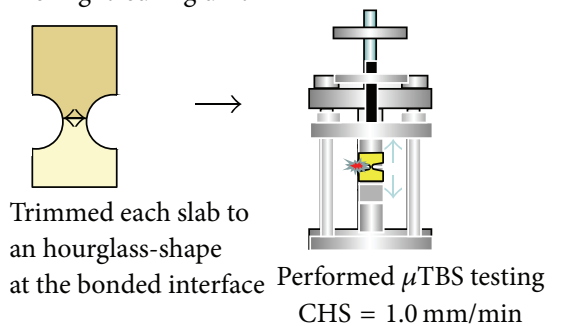

FIGURE 1: Schematic illustration of specimen preparation and $\mu$ TBS testing.

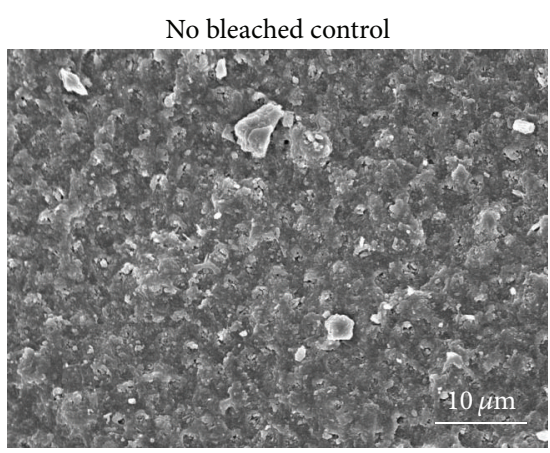

(a)

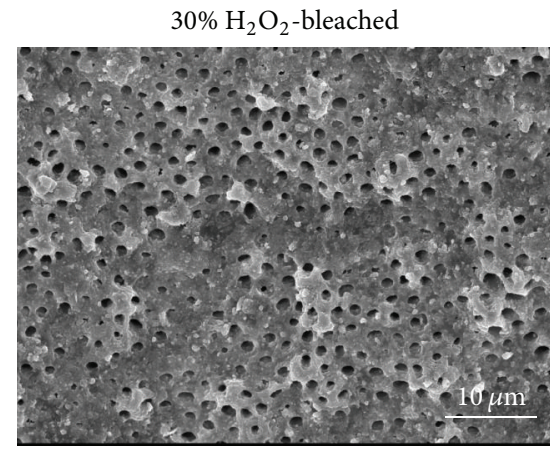

(b)

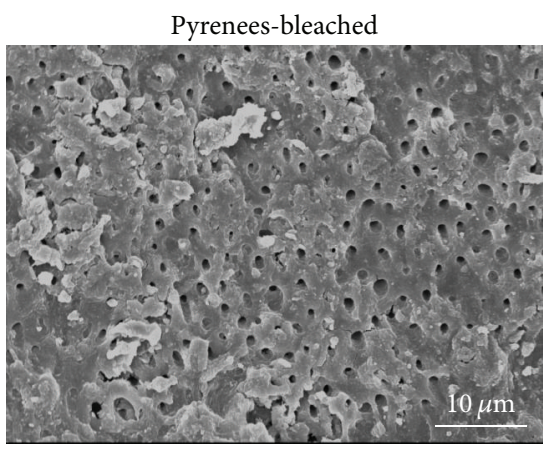

(c)

FIGURE 2: SEM images of pulp chamber dentin surface (1000x). Control: after immersion in distilled water. No dentinal tubules were exposed and the surface was entirely covered in debris. $30 \% \mathrm{H}_{2} \mathrm{O}_{2}$-bleached surface (Group 1): dentinal tubules were exposed and no debris were detected on the dentin surface. Pyrenees-bleached surface (Group 2): dentinal tubules were not as exposed as Group 1 and some debris were present covering the tubules.

tubules of Group 2 being exposed to a greater degree. Dentinal surface of control specimen was covered in smear debris and dentinal plugs were present (Figure 2(a)).

3.2. $\mu$ TBS. The mean $\mu$ TBS and SDs and the number of pretesting failures (ptf) in each group are summarized in Table 3 and graphically presented in box-whisker plots in
Figure 3. The $\mu$ TBS of control was significantly higher than both treated groups for both adhesive systems. In the control group, no significant difference in $\mu$ TBS was found between 1-SEA and 2-SEA. In Group 1, all 36 specimens from both adhesive systems failed before testing. In Group 2, $\mu$ TBS of 2-SEA was significantly greater compared to 1-SEA. For 1SEA, 21 out of 36 specimens failed before testing whereas no specimens failed in 2-SEA. 
TABLE 3: Microtensile bond strength (mean \pm SD, MPa) and the number of the pretesting failures $(n=36)$.

\begin{tabular}{lcc}
\hline & 1-SEA & 2-SEA $^{*}$ \\
\hline Control & $24.0 \pm 5.6^{\mathrm{a}}(0)$ & $26.5 \pm 9.8^{\mathrm{a}}(0)$ \\
Group 1 & $0.0 \pm 0.0^{\mathrm{d}}(36)$ & $0.0 \pm 0.0^{\mathrm{d}}(36)$ \\
Group 2 & $7.6 \pm 9.4^{\mathrm{c}}(21)$ & $17.3 \pm 5.8^{\mathrm{b}}(0)$ \\
\hline
\end{tabular}

The same superscript letters represent no statistical differences (TukeyKramer test; $p>0.05$ ).

${ }^{*} \mu$ TBS values of 2-SEA were cited from Haruyama et al., 2010 [13].

TABLE 4: Failure patterns in $\mu$ TBS specimens.

\begin{tabular}{rccccc}
\hline & Interfacial $^{\mathrm{a}}$ & Dentin $^{\mathrm{b}}$ & Resin $^{\mathrm{c}}$ & Mixed $^{\mathrm{d}}$ & Total \\
\hline Control & & & & & \\
1-SEA & 7 & 0 & 0 & 29 & 36 \\
2-SEA & 9 & 16 & 0 & 11 & 36 \\
Group 1 & & & & & \\
1-SEA & 36 & 0 & 0 & 0 & 36 \\
2-SEA & 36 & 0 & 0 & 0 & 36 \\
Group 2 & & & & & \\
1-SEA & 22 & 0 & 2 & 12 & 36 \\
2-SEA & 26 & 2 & 6 & 2 & 36 \\
\hline
\end{tabular}

${ }^{\mathrm{a}}$ Failure in the adhesive interface and/or failure within the hybrid layer.

${ }^{\mathrm{b}}$ Cohesive failure mainly within the dentin.

${ }^{\mathrm{c}}$ Cohesive failure mainly within the resin.

${ }^{\mathrm{d}}$ Mixture of interfacial and cohesive failures.

3.3. Failure Analysis. The representative SEM photomicrographs of the dentin-side of the fractured surface after $\mu$ TBS testing are shown in Figure 4. A mixture of cohesive failures in both dentin and composite regions was observed in a majority of cases (control, Figure 4(a)). Failures in the vicinity of adhesive interface were observed in both Group 1 and Group 2 (Figures 4(b) and 4(c), resp.) (Table 4).

\section{Discussion}

The purpose of this study was to evaluate the $\mu$ TBS of 1SEA and 2-SEA to pulp chamber dentin immediately after bleaching with 2 types of bleaching techniques. No significant differences in $\mu$ TBS were found between 1-SEA and 2-SEA in Group 1 using $30 \% \mathrm{H}_{2} \mathrm{O}_{2}$ whereas significant difference in $\mu$ TBS was found between the adhesive systems in Group 2 which used Pyrenees. From these results, the null hypothesis that there is no difference between the bonding behaviors of 1-SEA and 2-SEA on bleached dentin can be partially rejected.

In this study, $\mu$ TBS testing was used because it has been recognized as a suitable method for investigating resin bonding strength to pulpal dentin $[14,15]$. Reports have shown that resin bond strength to $\mathrm{H}_{2} \mathrm{O}_{2}$-treated intracoronal dentin is lower than that to nontreated dentin [16-18]. Inhibition of resin polymerization has been reported to be one of the reasons for lower resin bond strength to bleached tooth structure [18]. In addition to the obvious negative effects of insufficient bonding, residual resin monomer at the bonded interface may cause degradation which could potentially lead to the reoccurrence of tooth discoloration. For these reasons,

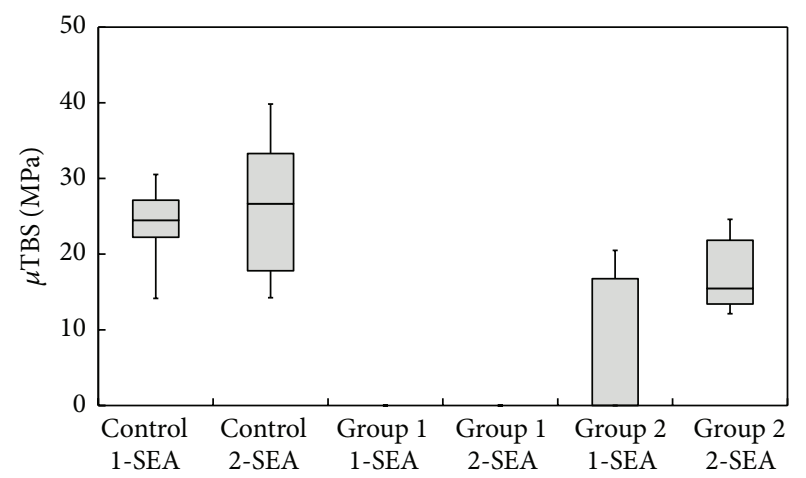

FIGURE 3: $\mu$ TBS of each group. The box represents the spreading of the data between the first and third quartile. The central vertical line represents the median. The whiskers denote the range of variance.

it is important to identify the appropriate adhesive system for optimal bonding.

There have been several reports that the bond strength of Clearfil S ${ }^{3}$ Bond to dentin was lower compared to Clearfil SE Bond $[19,20]$. This is inconsistent with our study where there was no significant difference between $\mu$ TBS of 1-SEA and 2$\mathrm{SEA}$ in the control group. The $\mathrm{pH}$ of Clearfil $\mathrm{S}^{3}$ Bond has been reported to be 2.7 [21], which is milder than Clearfil SE Bond; therefore, its effect on smear removal would be expected to be smaller yielding lower bonding strength. However, Ermis et al. [22] demonstrated that the $\mu$ TBS of Clearfil SE Bond and that of Clearfil $\mathrm{S}^{3}$ Bond to medium grit diamond bur-cut dentin were $60.3 \pm 14.8 \mathrm{MPa}$ and $8.4 \pm 9.0 \mathrm{MPa}$, respectively. In comparison, the $\mu \mathrm{TBS}$ to extrafine grit bur-cut dentin were 49.8 $\pm 18.6 \mathrm{MPa}$ and $34.4 \pm 22.3 \mathrm{MPa}$, respectively. In this study, the adhesive agent was applied to the pulp chamber dentin without grinding or cutting; therefore the lack of smear layer caused by grinding may have caused the $\mu$ TBS of 1-SEA and 2-SEA to be similar.

The $\mu$ TBS of 2-SEA was significantly higher than that of 1-SEA in Group 2. This can be explained in 2 reasons. Firstly, Clearfil SE Bond is well-known for its excellent bonding performance [23]. The $\mathrm{pH}$ of self-etching primer of Clearfil SE Bond is 1.9-2.0, which is categorized as a "mild" self-etch adhesive [21]. Instead of dissolving the smear layer, the selfetching primer of Clearfil SE Bond diffuses through the smear to produce a hybrid layer regardless of smear thickness [23]. The bonding phenomenon is a hypothesized model called the "AD concept" where MDP contained in the adhesive agent chemically bond to calcium ions decalcified from hydroxyapatite, which then copolymerize with the adhesive resin monomers [7, 24]. High filler content and high polymerization rate are responsible for the mechanical properties which contribute to its exceptional bonding performance [25-27]. Secondly, SEM images revealed high exposure of dentinal tubules in Group 1. According to studies, Clearfil $S^{3}$ Bond is more hydrophilic than Clearfil SE Bond; therefore, a deep monomer penetration of 1-SEA may lead to difficulty removing excess solvent (water and ethanol) causing incomplete polymerization $[19,20,28]$. This explanation is also substantiated by the cohesive failures observed within the 


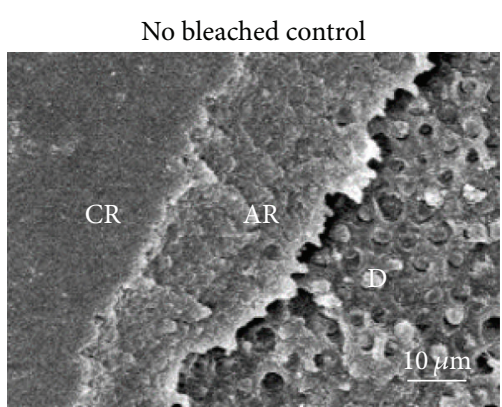

(a)

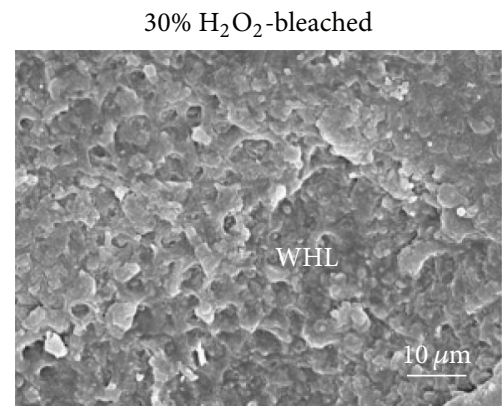

(b)

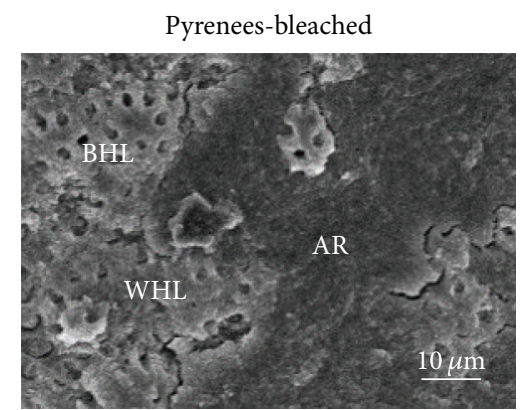

(c)

FIGURE 4: SEM images of fractured dentin-side surface of 1-SEA. (a) Control: mixture of the cohesive failures in composite resin (CR) and adhesive resin (AR) and interfacial failure between AR and dentin (D) can be observed. (b) Group 1: failure within the hybrid layer (WHL) can be seen. (c) Group 2: failure occurred within AR and within/at the bottom of the hybrid layer (WHL and BHL, resp.).

adhesive resin in the SEM images (Figure 4(a)). In Group 2, 21 out of 36 specimens failed before proper testing in 1-SEA whereas none failed when 2-SEA was used indicating that 2SEA is the better method for bonding resin to dentin after tooth bleaching.

Two types of bleaching techniques using $30 \% \mathrm{H}_{2} \mathrm{O}_{2}$, which is the conventional concentration used for walking bleach technique, and Pyrenees, a new photocatalytic activity technology using $\mathrm{TiO}_{2}$ and $3 \% \mathrm{H}_{2} \mathrm{O}_{2}$, were used in this study. Conventional bleaching agents contain a considerable amount of hydrogen peroxide $\left(\mathrm{H}_{2} \mathrm{O}_{2}\right)$ often causing cervical root resorption and damage to surrounding periodontal tissue $[29,30]$. The addition of $\mathrm{TiO}_{2}$ to bleaching agents followed by activation using a violet light source enhances the reaction of hydrogen peroxide $\left(\mathrm{H}_{2} \mathrm{O}_{2}\right)$ in the bleaching agent enabling the reduction of $\mathrm{H}_{2} \mathrm{O}_{2}$ from $30-35 \%$ to $3.5 \%$ [4]. As a result, serious side effects of residual oxygen may be reduced leading to fewer cases of cervical root resorption and periodontal damage [31].

An important finding was that all the specimens treated with $\mathrm{H}_{2} \mathrm{O}_{2}$-containing bleaching systems had significantly lower $\mu$ TBS compared to the control. A study suggests that the reduction in bond strength is due to the decreased mechanical strength of dentin as a result of the oxidizing effect of peroxide [32-34]. Our SEM results, however, did not support this hypothesis because no failure in dentin was observed. However, our results for reduced bonding of resin to $\mathrm{H}_{2} \mathrm{O}_{2}$ treated dentin can be explained by residual oxygen remaining in dentin pores after bleaching, which inhibits resin polymerization cured through the free radical mechanism [4]. In addition, the high acidity of hydrogen peroxide could have excessively demineralized the dentin surface affecting bonding strength [18].

In this study, not only did the specimens treated with conventional $30 \% \mathrm{H}_{2} \mathrm{O}_{2}$ fail before proper testing, but Pyrenees treated groups showed significantly higher $\mu \mathrm{TBS}$ compared to the conventional $\mathrm{H}_{2} \mathrm{O}_{2}$ treated group. The bleaching effect of Pyrenees has been reported to be equal to the walking bleach technique using $30-35 \% \mathrm{H}_{2} \mathrm{O}_{2}$ and sodium perborate [35, 36]. This indicates that bleaching agent containing $\mathrm{TiO}_{2}$ is a better alternative to the traditional walking bleach technique from the viewpoint of safety and adhesive dentistry.
In this study, resin was bonded to dentin immediately after bleaching; however, delayed bonding and the application of antioxidants on treated surfaces to reverse the damage of $\mathrm{H}_{2} \mathrm{O}_{2}$ on the dentin surface are areas of further interest when considering the situation in a clinical setting [37].

\section{Conclusion}

This study evaluated the $\mu$ TBS of 1-SEA and 2-SEA to pulp chamber dentin immediately after bleaching with 2 types of common bleaching techniques. In the $30 \% \mathrm{H}_{2} \mathrm{O}_{2}$ treated groups, all specimens failed before proper bonding tests. In the Pyrenees treated group, the $\mu$ TBS of 2-SEA was significantly greater, with no failed specimens, than 1-SEA where 21 out of 36 specimens failed. These results therefore indicate that 2-SEA is a better adhesive system than 1SEA on bleached dentin. Our results also demonstrated that application of $\mathrm{H}_{2} \mathrm{O}_{2}$ significantly decreases bonding strength of resin to dentin; however, in the case of bleaching nonvital tooth, Pyrenees is a better alternative to the conventional $30 \%$ $\mathrm{H}_{2} \mathrm{O}_{2}$ bleaching agent.

\section{Competing Interests}

The authors have no financial relation to any of the companies whose products are included in this article.

\section{Acknowledgments}

The authors thank Mr. K. Tadokoro (Oral Health Science Center, Tokyo Dental College) for his technical assistance of SEM. This work was partially supported by a Grant-in-Aid for Scientific Research from MEXT, Japan ((B) 16K20464 and (C) 25462466).

\section{References}

[1] E. B. Nutting and G. S. Poe, "Chemical bleaching of discolored endodontically treated teeth," Dental Clinics of North America, vol. 11, pp. 655-662, 1967.

[2] E. Anitua, B. Zabalegui, J. Gil, and F. Gascon, "Internal bleaching of severe tetracycline discolorations: four-year clinical 
evaluation," Quintessence International, vol. 21, no. 10, pp. 783788, 1990.

[3] T. Nakazawa, J. Kato, G. Akashi, A. Igarashi, and Y. Hirai, "Effect of tooth bleaching on low concentration hydrogen peroxide containing titanium dioxide photocatalyst," The Japanese Journal of Conservative Dentistry, vol. 50, no. 5, pp. 562-569, 2007.

[4] K. Sakai, J. Kato, H. Kurata et al., "The amounts of hydroxyl radicals generated by titanium dioxide and 3.5\% hydrogen peroxide under 405-nm diode laser irradiation," Laser Physics, vol. 17, no. 8, pp. 1062-1066, 2007.

[5] T. Suemori, J. Kato, T. Nakazawa, G. Akashi, and Y. Hirai, "A new non-vital tooth bleaching method using titanium dioxide and $3.5 \%$ hydrogen peroxide with a $405-\mathrm{nm}$ diode laser or a halogen lamp," Laser Physics Letters, vol. 5, no. 6, pp. 454-459, 2008.

[6] Y. Suyama, M. Otsuki, S. Ogisu et al., "Effects of light sources and visible light-activated titanium dioxide photocatalyst on bleaching," Dental Materials Journal, vol. 28, no. 6, pp. 693-699, 2009.

[7] B. Van Meerbeek, K. Yoshihara, Y. Yoshida, A. Mine, J. De Munck, and K. L. Van Landuyt, "State of the art of self-etch adhesives," Dental Materials, vol. 27, no. 1, pp. 17-28, 2011.

[8] J. De Munck and B. Van Meerbeek, "The current status of bonding to dentin anno 2007," International Journal of OralMedical Sciences, vol. 6, no. 2, pp. 45-60, 2007.

[9] J. Perdigão, "New developments in dental adhesion," Dental Clinics of North America, vol. 51, no. 2, pp. 333-357, 2007.

[10] J. De Munck, B. Van Meerbeek, M. Vargas et al., "One day bonding effectiveness of new self-etch adhesives to bur-cut enamel and dentin," Operative Dentistry, vol. 30, no. 1, pp. 3949, 2005.

[11] Y. Kotoku, J. Kato, G. Akashi, Y. Hirai, and K. Ishihara, "Bactericidal effect of a 405-nm diode laser on Porphyromonas gingivalis," Laser Physics Letters, vol. 6, no. 5, pp. 388-392, 2009.

[12] A. Kameyama, H. Hatayama, J. Kato et al., "Light-curing of dental resins with GaN violet laser diode: the effect of photoinitiator on mechanical strength," Lasers in Medical Science, vol. 26, no. 3, pp. 279-283, 2011.

[13] A. Haruyama, J. Kato, A. Kameyama, Y. Hirai, and Y. Oda, "Effect of titanium dioxide and 3.5\% hydrogen peroxide with 405-nm diode laser irradiation on bonding of resin to pulp chamber dentin," Laser Physics, vol. 20, no. 4, pp. 881-885, 2010.

[14] H. Sano, T. Shono, H. Sonoda et al., "Relationship between surface area for adhesion and tensile bond strength-evaluation of a micro-tensile bond test," Dental Materials, vol. 10, no. 4, pp. 236-240, 1994.

[15] G. C. Lopes, P. De Carvalho Cardoso, L. C. C. Vieira, and L. N. Baratieri, "Microtensile bond strength to root canal vs pulp chamber dentin: effect of bonding strategies," Journal of Adhesive Dentistry, vol. 6, no. 2, pp. 129-133, 2004.

[16] F. F. Demarco, M. L. Turbino, A. G. Jorge, and E. Matson, "Influence of bleaching on dentin bond strength," American Journal of Dentistry, vol. 11, no. 1, pp. 78-82, 1998.

[17] H. Elkhatib, M. Nakajima, N. Hiraishi, Y. Kitasako, J. Tagami, and S. Nomura, "Surface $\mathrm{pH}$ and bond strength of a self-etching primer/adhesive system to intracoronal dentin after application of hydrogen peroxide bleach with sodium perborate," Operative Dentistry, vol. 28, no. 5, pp. 591-597, 2003.

[18] S. Nomoto, A. Kameyama, T. Nakazawa et al., "Influence of ascorbic acid on bonding of peroxide-affected dentin and 4META/MMA-TBB resin," Clinical Oral Investigations, vol. 10, no. 4, pp. 325-330, 2006.
[19] A. Kameyama, K. Aizawa, J. Kato, and Y. Hirai, “Tensile bond strength of single-step self-etch adhesives to Er:YAG laserirradiated dentin," Photomedicine and Laser Surgery, vol. 27, no. 1, pp. 3-10, 2009.

[20] K. L. Van Landuyt, A. Mine, J. De Munck et al., "Are one-step adhesives easier to use and better performing? Multifactorial assessment of contemporary one-step self-etching adhesives," The Journal of Adhesive Dentistry, vol. 11, no. 3, pp. 175-190, 2009.

[21] K. Koshiro, S. K. Sidhu, S. Inoue, T. Ikeda, and H. Sano, "New concept of resin-dentin interfacial adhesion: the nanointeraction zone," Journal of Biomedical Materials Research Part B: Applied Biomaterials, vol. 77, no. 2, pp. 401-408, 2006.

[22] R. B. Ermis, J. De Munck, M. V. Cardoso et al., "Bond strength of self-etch adhesives to dentin prepared with three different diamond burs," Dental Materials, vol. 24, no. 7, pp. 978-985, 2008.

[23] F. R. Tay and D. H. Pashley, "Aggressiveness of contemporary self-etching systems. I. Depth of penetration beyond dentin smear layers," Dental Materials, vol. 17, no. 4, pp. 296-308, 2001.

[24] Y. Yoshida, K. Nagakane, R. Fukuda et al., "Comparative study on adhesive performance of functional monomers," Journal of Dental Research, vol. 83, no. 6, pp. 454-458, 2004.

[25] M. Cadenaro, F. Antoniolli, S. Sauro et al., "Degree of conversion and permeability of dental adhesives," European Journal of Oral Sciences, vol. 113, no. 6, pp. 525-530, 2005.

[26] A. Kameyama, J. Kato, M. Yoshinari, Y. Kotoku, G. Akashi, and Y. Hirai, "Ultimate micro-tensile strength of dental adhesives cured at different light source," Journal of Photopolymer Science and Technology, vol. 21, no. 1, pp. 31-35, 2008.

[27] A. Kameyama, J. Kato, J. De Munck et al., "Light-curing efficiency of dental adhesives by gallium nitride violet-laser diode determined in terms of ultimate micro-tensile strength," Bio-Medical Materials and Engineering, vol. 21, no. 5-6, pp. 347356, 2011.

[28] H. Abo, A. Kameyama, and A. Haruyama, "Clinical observation of the tooth surface during air-drying of self-etching primer under 3D video microscope," Applied Adhesion Science, vol. 4, article 7, 2016.

[29] G. W. Harrington and E. Natkin, "External resorption associated with bleaching of pulpless teeth," Journal of Endodontics, vol. 5, no. 11, pp. 344-348, 1979.

[30] M. Trope, "Cervical root resorption," Journal of the American Dental Association, vol. 128, supplement, pp. 56S-59S, 1997.

[31] D. Dietschi, "Nonvital bleaching: general considerations and report of two failure cases," The European Journal of Esthetic Dentistry, vol. 1, no. 1, pp. 52-61, 2006.

[32] C. D. Torneck, K. C. Titley, D. C. Smith, and A. Adibfar, "Adhesion of light-cured composite resin to bleached and unbleached bovine dentin," Endodontics \& Dental Traumatology, vol. 6, no. 3, pp. 97-103, 1990.

[33] I. Lewinstein, Z. Hirschfeld, A. Stabholz, and I. Rotstein, "Effect of hydrogen peroxide and sodium perborate on the microhardness of human enamel and dentin," Journal of Endodontics, vol. 20, no. 2, pp. 61-63, 1994.

[34] L. E. Tam and A. Noroozi, "Effects of direct and indirect bleach on dentin fracture toughness," Journal of Dental Research, vol. 86, no. 12, pp. 1193-1197, 2007.

[35] T. Nakazawa, J. Kato, T. Suemori et al., "Non-vital bleach method using low-concentration hydrogen peroxide with titanium dioxide," The Japanese Journal of Conservative Dentistry, vol. 51, no. 1, pp. 82-87, 2008. 
[36] T. Nonami, K. Ishibashi, T. Ishibashi, and O. Kondo, "Bleaching of $\mathrm{TiO}_{2}$ photocatalyst: part 1. Color alteration and microstructural changes by bleaching," The Japanese Journal of Conservative Dentistry, vol. 44, no. 1, pp. 37-43, 2001.

[37] H. H. Whang and D. H. Shin, "Effects of applying antioxidants on bond strength of bleached bovine dentin," Restorative Dentistry \& Endodontics, vol. 40, no. 1, pp. 37-43, 2015. 

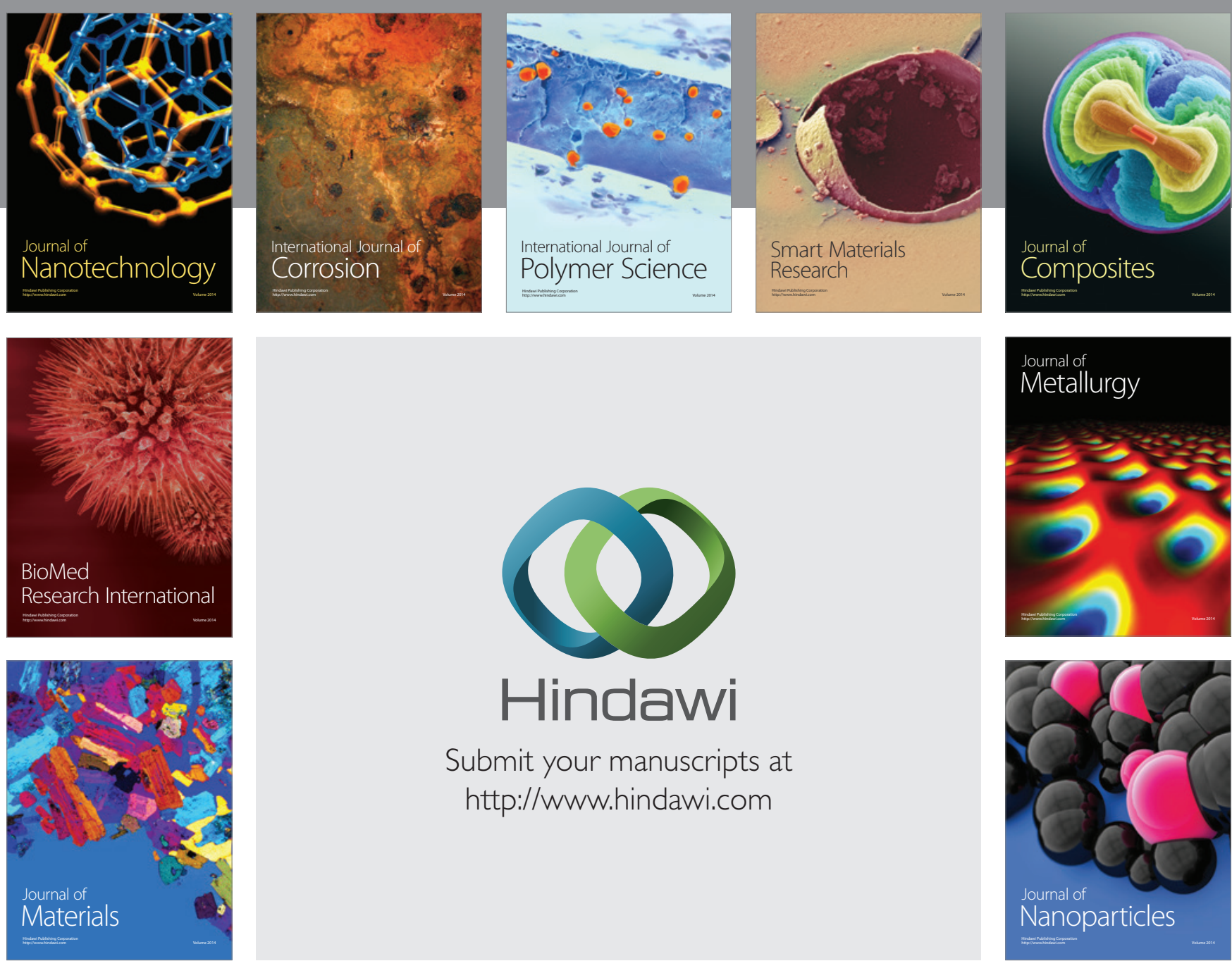

\section{Hindawi}

Submit your manuscripts at

http://www.hindawi.com

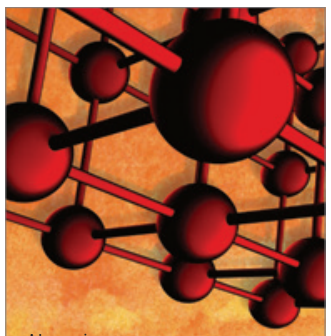

Materials Science and Engineering
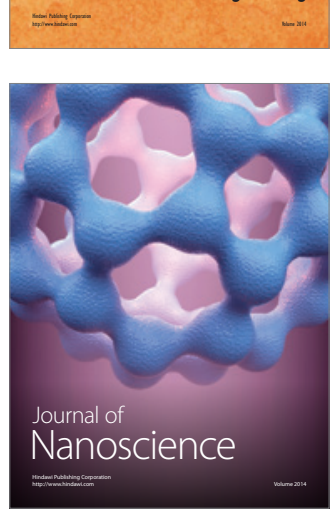
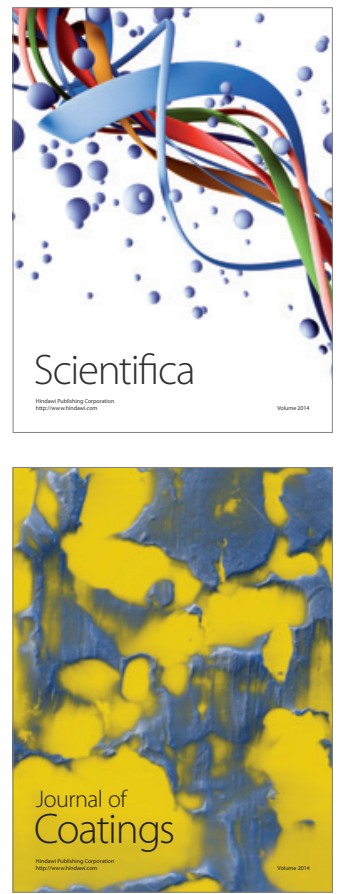
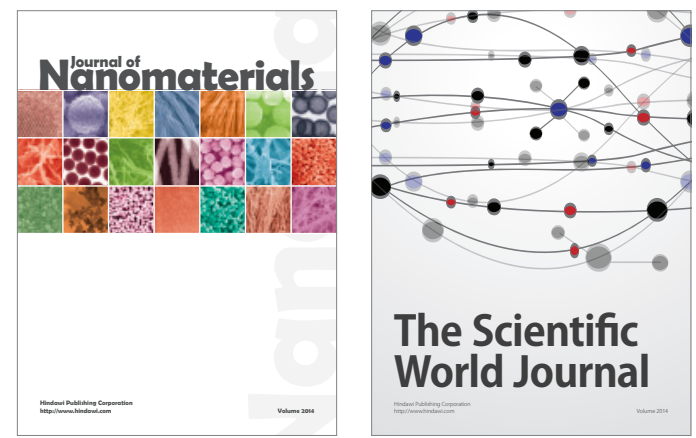

The Scientific World Journal
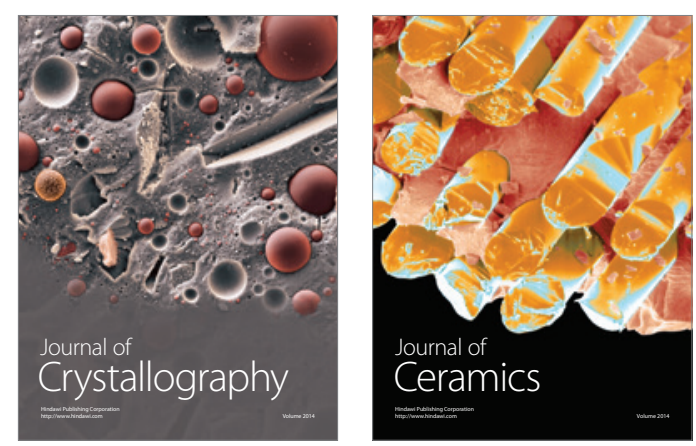
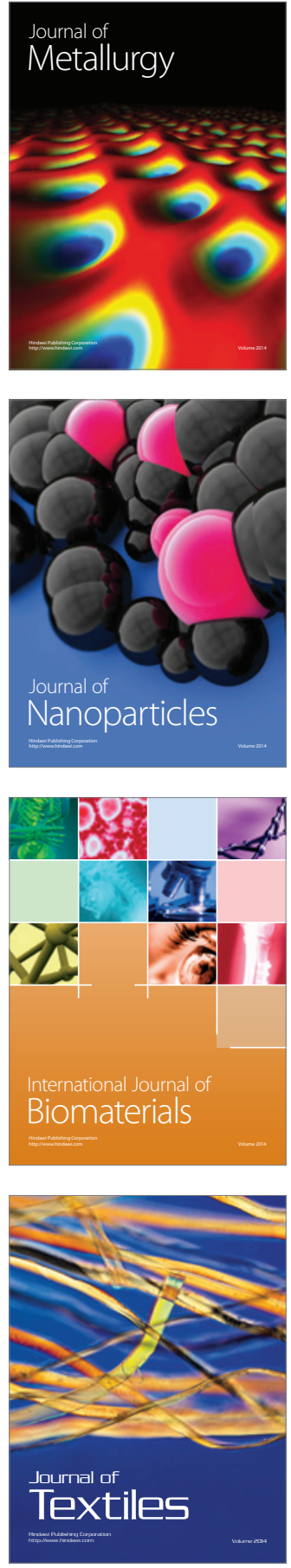